\title{
The Importance of Under-Keel Sound Velocity Sensor in Measuring Water Depth with Multibeam Echosounder
}

\author{
Artur Grządziel iD \\ Department of Navigation and Hydrography, Faculty of Navigation and Naval Weapons, Polish Naval Academy, \\ 81-127 Gdynia, Poland; a.grzadziel@amw.gdynia.pl
}

check for

updates

Citation: Grządziel, A. The Importance of Under-Keel Sound Velocity Sensor in Measuring Water Depth with Multibeam Echosounder. Energies 2021, 14, 5267. https:// doi.org/10.3390/en14175267

Academic Editor: Antonio Zuorro

Received: 28 July 2021

Accepted: 23 August 2021

Published: 25 August 2021

Publisher's Note: MDPI stays neutral with regard to jurisdictional claims in published maps and institutional affiliations.

Copyright: (C) 2021 by the author. Licensee MDPI, Basel, Switzerland. This article is an open access article distributed under the terms and conditions of the Creative Commons Attribution (CC BY) license (https:/ / creativecommons.org/licenses/by/ $4.0 /)$.

\begin{abstract}
The basic and most commonly used application of modern multibeam echosounders (MBES) is the bathymetric survey. Surface sound velocity errors introduce errors on beam steering angles and consequently errors in depth and position values. Due to systematic malfunction and troubleshooting of the sound velocity sensor (SVS) on board Polish Navy hydrographic ship Arctowski, attempts to solve the problem were made. All the inspections and cleaning of the sensor were performed with the use of divers or while staying in the shipyard. Diving work did not always bring the expected results and periodic ship docking was quite expensive. The article shows the importance of the SVS sensor in bathymetric measurements using multibeam echosounder. Selected problems of the sensor operation and temporary solutions were presented. The paper provides a description of practical solutions implemented aboard the navy ship Arctowski. The idea and implementation were the result of the author's experience gained during 18 years of service on board that ship.
\end{abstract}

Keywords: water depth measurements; sound velocity sensor; multibeam echosounder

\section{Introduction}

Man's pursuit to explore the ocean seabed began a new science called Hydrography, which was born over 3700 years ago [1]. Although two thirds of the Earth's surface is covered by the world's oceans, only a small part has been mapped by direct measurements [2]. The dimension of the seabed is simply too vast and current resources too limited to fully depict every meter of underwater surface [3]. A huge majority of oceans and seas are still not sensed nor explored. In spite of the introduction of new and advanced survey techniques, the depth of the ocean has been measured over less than $18 \%$ of the sea bottom using acoustic devices at a resolution of about $1 \mathrm{~km} \mathrm{[4].} \mathrm{Only} \mathrm{10 \%} \mathrm{have} \mathrm{been} \mathrm{surveyed}$ by means of modern remote sensing technology and another $5 \%$ were mapped with lead lines [5].

The scientists, navigators and mariners have measured the depths beneath the ships for thousands of years, mainly for safe navigation [6,7]. During the last four or five decades, hydrographic research has undergone major changes in methodology and technology of surveying. The single-beam echosounder that was developed in the 1930s is still in widespread use [8,9]. Echosounders with multiple beams became publicly available in the 1970s [10] with the development of a satellite global positioning system (GPS). These systems, called multibeam echosounders, operate on much the same principle to single-beam echosounders, except that they transmit and receive many individual acoustic beams in a wide swath perpendicular to the direction of movement [11-13]. Sound waves generated by these systems propagate obliquely what makes them sensitive to the refraction phenomenon [14]. MBESs ensure practically complete bottom coverage, high data density and recording rates [15]. Regardless of their imposing capabilities, it is extremely important that scientists, hydrographers and operators have a thorough knowledge of how MBES works, what are the measurements errors and their causes [16].

The basic and most commonly used application of modern multibeam echosounders is the bathymetric survey $[7,17]$. The ability to record depth simultaneously in several 
hundred points of the bottom along with related positions is undoubtedly the advantage of this device. Measurements obtained with this method are used in many scientific fields, among others for classification and acoustic imaging of the seabed [18-21], learning about bottom sediment processes [22], identifying geotechnical hazards and gas leaks from the bottom [23], as well as exploring the marine habitat [24,25]. MBES is widely used by hydrographic services, maritime administration, dredging companies, military users and commercial firms dealing with hydrographic surveys [26].

Swath mapping systems can be installed on a vessel, small boat, underwater vehicle, remotely operated vehicle (ROV) or a remote surface vehicle [27]. A multibeam sonar acquisition system, besides the echosounder, consists inter alia of an attitude sensor, an inertial measurement unit (IMU) and a pair of GPS receivers with appropriate antennas [28]. In addition to above two sound velocity sensors should be mentioned: sound velocity profiler-measuring the sound velocity in the water column; sound velocity sensor-measuring the surface sound velocity $[15,29]$.

The depth measurement accuracy depends on various factors and is the outcome of processing information from various sources. The basic measurements in the MBES system are the measurement of the distance that the acoustic pulse travels from the transducer to the seafloor and back, as well as the electronic measurement of the steering angle of the echo signal for each beam [30]. The accuracy of the recorded data depends on the knowledge about the water column characteristics through which the signal propagates. The data recorded by the sound velocity sensor and the sound velocity profiler is crucial for the accuracy of depth measurement. Changes of the sound propagation conditions in the water (e.g., temperature or salinity) can significantly affect the uncertainty of bathymetric measurements and therefore also the reliability of nautical charts [1].

In recent years, there has been a challenge to limit possible depth measurement errors. The prevailing error that remains to be resolved satisfactorily is caused by incomplete knowledge of the environment characteristics and the associated changes of sound velocity in the water column. This results in unknown propagation and refraction error, which is often present in shallow water multibeam survey [13,31,32].

The Technical Note is structured as follows. The introduction to the study, purpose and key publications cited are provided in Section 1. Section 2 details the importance of the sound velocity in the water for the accuracy of the multibeam bathymetric measurements. Section 3 presents the ways of mounting the MBES transducers and SVS sensors, MBES system on board Polish Navy ship and causes of SVS malfunction as well as ad hoc solutions. The final technical concept was shown in Section 4. Section 5 concludes the paper.

\section{The Importance of Sound Velocity in the Water for the Accuracy of Multibeam Bathymetry}

Despite the fact that many important improvements have been made to the sensor accuracy over the last decades, the effectiveness and accuracy of the survey is still limited by inadequate knowledge of the underwater environment. When performing multibeam survey, usually two sets of sound velocity readings are taken [14]. The first set comprises the sound velocity near the MBES transducer array, which is typically measured with a sensor under the keel of the vessel. These sound velocity values are utilized for the beamsteering technique. The second set contains sound velocity profiles obtained with a Conductivity-Temperature-Depth (CTD) probe. Sound velocity profiles are indispensable for determining the trajectory of sound wave through the water column, essential for deriving the depth value from the measured travel-times [33,34].

Errors in sound velocity will cause different errors depending on their nature and on the transducer configuration of the multibeam echosounder. The errors due to sensor offsets and varying sound velocity at the transducer depth, depend upon transducer configuration, or on how much electronic beam steering is applied [35]. For a curved or semi-circular transducer array, no or only a limited amount of electronic beam steering is required. For a linear or flat transducer array, electronic beam steering is always applied except for the beam normal to the transducer. 
Sound speed at the depth of the transducer face of the multibeam echosounder and its variability in the water column must be measured to correct the acoustic pulse travel time. Raytrace estimation of the pulse, utilizing Snell's law, determines the spot where the pulse hits the sea bottom. Without the correction for sound velocity, the bathymetry data would include vertical and horizontal uncertainties due to refraction. Swath sounding systems are more susceptible to refraction error than vertical beam echosounders due to the variable incident angle of the acoustic waves on the interface between layers of different water densities [36]. Applying an incorrect sound speed value to raytracing results in changes to the bottom profile. Seabed line tends to tilt up or down on the outer beams ("smile" and "frown" artifacts). The difference between depth values alongside the swath can be meaningful, even up to tens of centimeters (Figure 1).

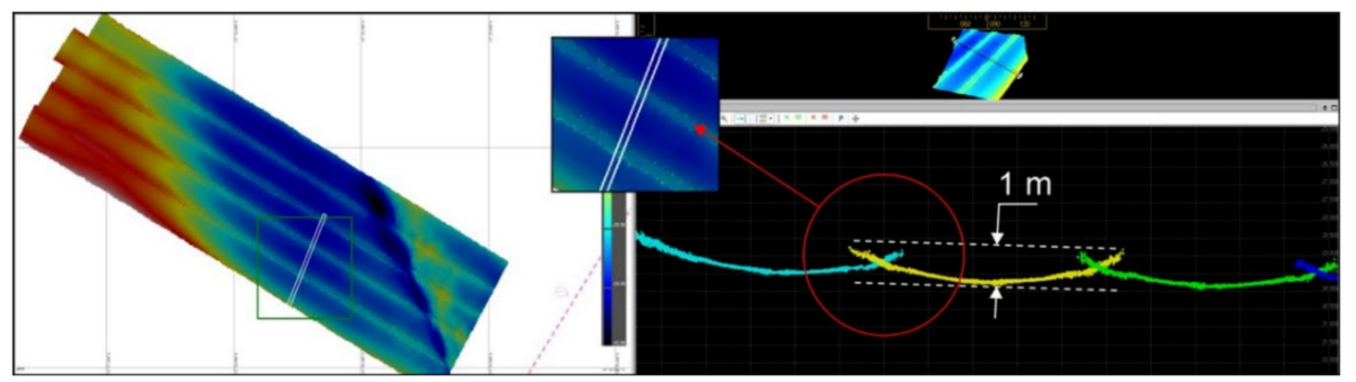

Figure 1. The effect of using incorrect sound velocity values on the accuracy of depth measurement.

Refraction artifacts are common in shallow water surveys and can seriously degrade the quality of the final bathymetric map if not properly addressed. A continuous monitoring of the physical characteristics of the sea water would avoid the occurrence of this artifact. However, it is actually impossible to fully control the variations of speed of sound in time and space [37]. The effect of acoustic ray refraction is stronger for oblique beams. This can be considerably compensated by the sound speed profiles. However, there are typically some remaining errors due to the uncertainty in observation of these profiles, and small changes over time [38].

A sound velocity profile (SVP) should be measured within the study area at the minimum once before the survey starts and at least once after finish. There are areas where many SVPs casts should be taken. Freshwater inflows from rivers in the proximity of estuaries will cause changes in distribution of sound velocity profiles [37].

The sound speed measured at the transducer depth (called surface sound speed), is required in the multibeam echosounder beamsteering process, which allows a beam to be directed to a requested angle, that is oblique to the multibeam transducer. Beamsteering technique differs depending on the type of transducer used. Currently, two basic methods of steering the beams are physical and electronic. Physical beamsteering uses an array that is mechanically shifted to point in the requested bearing, or the echosounder may be composed of multiple acoustic elements, with each individual transducer directed at the discrete location. Electronic control is done by digitizing the signal and calculating beams at the requested angles. Depth values are computed based on the amplitude of the receiving signal, and beam characteristics are determined by real shape of the acoustic array elements.

To assure correct beamsteering process with linear hydrophone arrays a surface sound velocity sensor is required [33,35,39]. The probe measures the sound velocity at the depth of MBES's head continuously during hydrographic survey. The measurement is combined to the multibeam echosounder transceiver to electronically steer the acoustic beams during transmission from flat transducer array [40]. It is also applied to increase the sound velocity profile during ray tracing by using the measured surface value as "the initial entry in the sound speed profile for the ray tracing computations" [41] or calculating Snell's constant with the measured value before ray tracing [42]. For MBES with curved receive transducers, beamsteering only occurs for sectors beyond the angle where a symmetric array of elements 
is available. For flat transducers, beamsteering occurs for all beams except the one normal to the array.

Electronic beamsteering is essentially based on electronic filter methods to distinguish individual echo signals coming from various directions. This allows to create a full set of acoustic beams with each transmit-receive period. These electronic techniques "virtually" control the receive beams. In the case of linear array transducer, two basic techniques are time or phase delay and fast Fourier transform technique (FFT). Electronic beamsteering uses the fact that transducers are not one individual element but consist of many single elements, that can be monitored and controlled [43].

For beamsteering or beam stabilization, it is necessary to insert time delays in the transducer elements. To calculate the time delays, one needs to know the speed of sound near the transducer face, which is provided by a sound velocity sensor mounted nearby the transducer. Any surface sound velocity error at the transducer array will be distributed as an error in the beamsteering angle $d \theta_{k}$ (Figure 2).

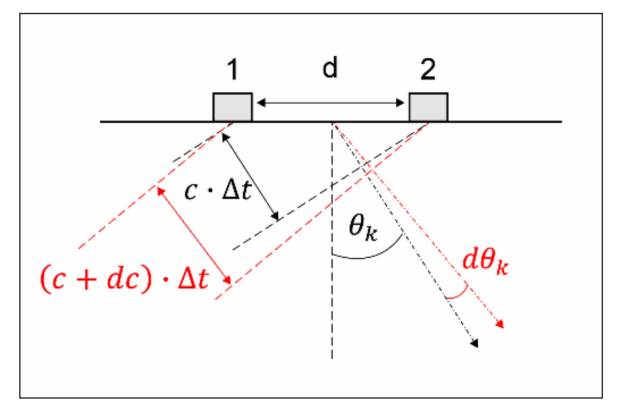

Figure 2. Beam steering error $d \theta_{k}$ due to sound velocity variation $d c$. 1,2-transducer elements. d-fixed element spacing.

An acoustic wave hits each transducer element, but at a various time and phase depending on the receiving angle of the return. By introducing an alternating delay to each hydrophone element's information, the phases can be aligned and the single beam can be steered in the desired bearing. To correctly apply the time delay, certain factors must be known or measured: (1) the spacing between receiving transducer elements, (2) the time of signal reception by individual element, and (3) the value of speed of sound measured near the transducer array. The distance between acoustic elements, and signal frequency are established by the manufacturer. The wavelength is a function of surface sound speed. If the sound speed applied to compute the wavelength is erroneous, the time delays values will direct the beam at a wrong angle. This is extremely important when measuring in areas where physical properties of sea water are unforeseeable and changeable (e.g., estuaries).

From Figure 2 it can be seen that for a flat acoustic array to steer the beam nonperpendicular to the transducer face by an angle of $\theta_{k}$, we can use the length of the transducer segment used for beamforming $d$ and the sound velocity in water $c$ to calculate the time delay $\Delta t$. The following relationship holds:

$$
\sin \theta_{k}=\frac{c \cdot \Delta t}{d}=c \cdot \frac{\Delta t}{d}
$$

By differentiating Equation (1) we obtain:

$$
d \theta_{k}=\frac{\Delta t}{\sqrt{d^{2}-(\Delta t \cdot c)^{2}}} d c
$$

Based on the Equation (1) we know that:

$$
c \cdot \Delta t=d \cdot \sin \theta_{k}
$$


and performing substitution we can see the error in the angle $\theta_{k}$ caused by an error in surface sound speed:

$$
d \theta_{k}=\tan \theta_{k} \frac{d c}{c}
$$

where $d c$ represents the error in sound speed measured at the hydrophone array.

If we know the time alterations, one is able to make the hydrophone system have maximum sensitivity at angle of $\theta_{k}$, adding up single hydrophone readings slightly shifted in time, so that the wave fronts constructively interfere. This is called applying a time delay. This entails the main lobe of the beam pattern altering in such a way that its axis is at an angle $\theta_{k}$ from the perpendicular. By using time or phase delays for hydrophone array readings and adding up the array can be direct to maximize its sensitivity to any angle $\theta_{k}$. In the case of a barrel kind of transducer head, real shape of the array sets the opening angle. Since no electronic control is required, changes in the speed of the sound at the transducer do not affect the opening angle.

From the Equation (1) time delay on $n$th element can be calculated:

$$
\Delta t_{n}=\frac{n \cdot d}{c} \cdot \sin \theta_{k}
$$

All these methods involve the use of a number of elements arranged in a line at a known distance from each other, this distance equals a constant multiple of the wavelength $\lambda$. Assuming the sound velocity is:

$$
c=\frac{\lambda}{t}=\lambda \cdot f
$$

where $\lambda$ is wavelength, $f$ is frequency of acoustic wave, the time delay beamforming can be calculated:

$$
\Delta t_{n}=\frac{n \cdot d}{\lambda \cdot f} \cdot \sin \theta_{k}
$$

If we do not know exactly the wavelength $\lambda$ (erroneous sound speed), the angle estimates will be slightly incorrect $d \theta_{k}$ (Figure 3 ).

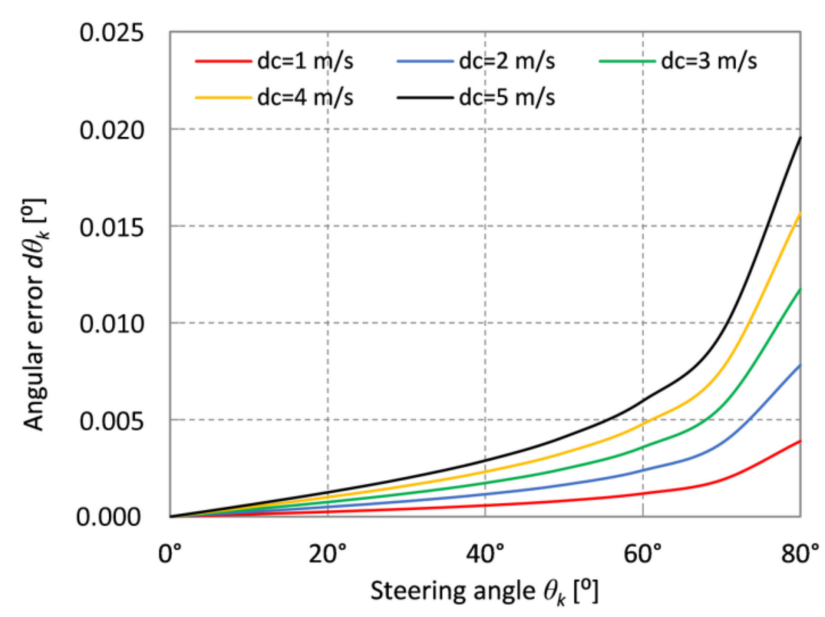

Figure 3. Beam steering sensitivity to surface sound speed error.

Outer beams of the multibeam echosounder are subject to greater angular error $d \theta_{k}$ than the inner beams. The increased uncertainty of depth measurement in the oblique beams forces the necessity to limit the usable swath angle of the multibeam system while performing bathymetric survey. 
The resulting depth errors $d z$ in case of MBES system with tilted transducers and electronic beamsteering is [35]:

$$
d z=\frac{\Delta c \cdot D}{c} \cdot \tan \theta_{k} \cdot\left[\tan \theta_{k}-\tan \left(\theta_{k}-\beta-R\right)\right]
$$

where $D$ is the depth, $\beta$ is the transducer tilt angle and $R$ is roll angle.

As one can easily guess, the accuracy of final depth measurements depends not only on the accuracy of surface sound velocity. For the transducers with the electronic beamsteering and tilted sideways the actual depth of surveying and roll angle will influence the bathymetric data quality. Figure 4 shows the impact of surface velocity on the accuracy of depth measurement and Figure 5 presents the impact of inaccurate surface sound velocity and effects of variable depths.

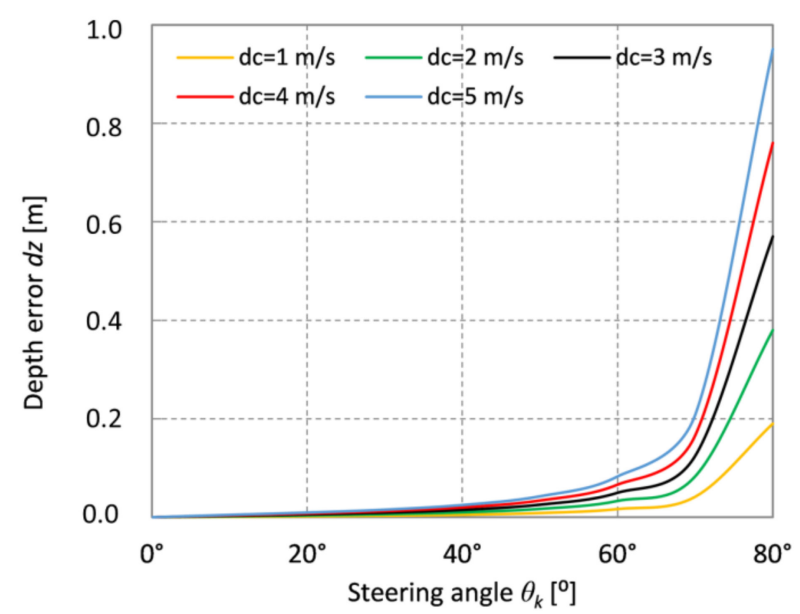

Figure 4. The impact of inaccurate surface sound velocity on the accuracy of depth measurement. Calculation made for the following input data: $c=1450 \mathrm{~m} / \mathrm{s}, \beta=40^{\circ}, R=1^{\circ}, D=10 \mathrm{~m}$.

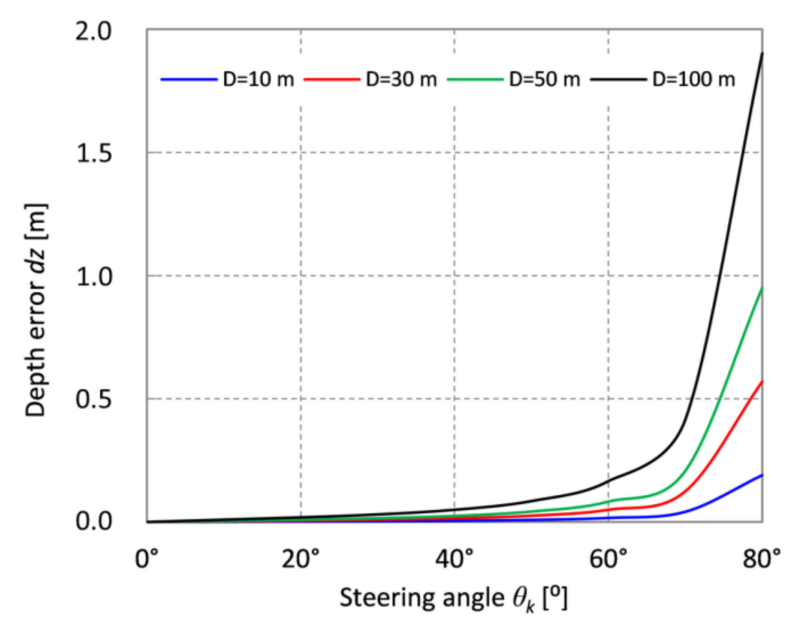

Figure 5. The impacts of inaccurate surface sound velocity and different water are on the accuracy of depth measurement. Calculation made for the following input data: $c=1450 \mathrm{~m} / \mathrm{s}, \beta=40^{\circ}, R=1^{\circ}$, $D=10,30,50$, and $100 \mathrm{~m}$.

\section{Material and Methods}

Multibeam echosounder systems are currently one of the most effective hydroacoustic means for large-scale bathymetric surveys ensuring full bottom coverage. An inherent component of the hydrographic survey system based on MBES is a sound velocity sensor. The mounting method and location of this sensor depends largely on the technique of using 
the multibeam echosounder. This, in turn, depends on the type and size of the transducer, size of the vessel and the shape of the underwater part of the hull $[15,28]$.

\subsection{Ways of Mounting the MBES Tranducers and Sound Velocity Sensors}

There are basically two techniques of transducer mount: fixed installation to the vessel hull (fixed transducers) and temporary (portable) mounting. The "permanent" installation of the transducer to the hull (hull-mounted installation) is an option that is most often used on larger vessels (over $12 \mathrm{~m}$ in length), systematically performing a large-scale offshore survey or deep-water ocean research [15]. These units are characterized by a high side and a long stem, which often prevents the external mounting of the transducer over the side or bow of the vessel. Flat-bottomed vessels are recommended to be equipped with flush-mounted transducers (Figure 6a). The face of the transducer is most often flush and built into the keel of the ship. An unquestionable advantage of this method of assembly is the fact that no additional steel structure is required for placing the transducer in $[44,45]$.

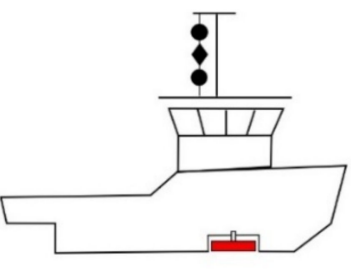

(a)

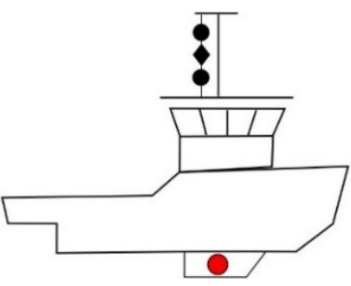

(b)

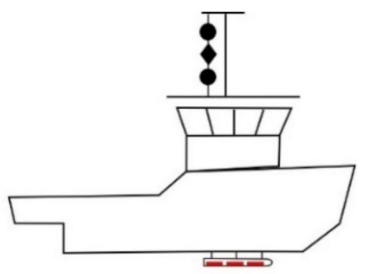

(c)

Figure 6. Ways of mounting the MBES transducer to the hull. (a) Flush-mount; (b) blister installation; (c) gondola installation.

If the shape of the underwater part of the hull makes it impossible to use flushmount installation, the transducers are placed in special structures called blister and gondola (Figure $6 \mathrm{~b}, \mathrm{c}$ ). On the one hand, such solutions allow to reduce the impact of disturbances and noise from the flowing stream of water. On the other hand, blister or gondola installation increase the ship's draft, sometimes even by tens of centimeters.

A moon pool is very often used on double-hull catamarans. It is an opening in the bottom of the hull, providing access to the water, through which a special boom with a transducer and other sensors is lowered and raised (Figure 7). The transducer is mounted near the vessel's center of gravity in the laminar flow zone. A hydraulic drive is most often used to lower the sonar head to a given depth. It is important that the structure is rigid and stable and that the transducer has a fixed, unchanging position when fully extended to the survey position. When no measurements are taken, the transducer is lifted and hidden in a special protective installation trunk. This method of installation provides the user with direct access to the transducer and facilitates visual inspection or repair.

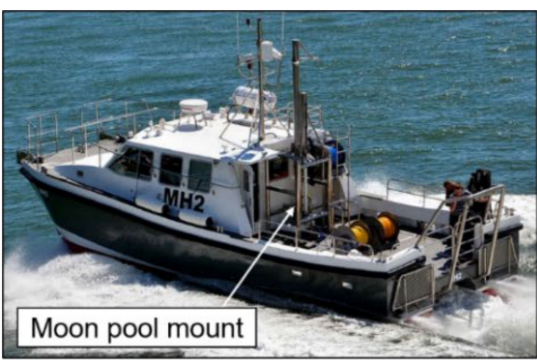

(a)

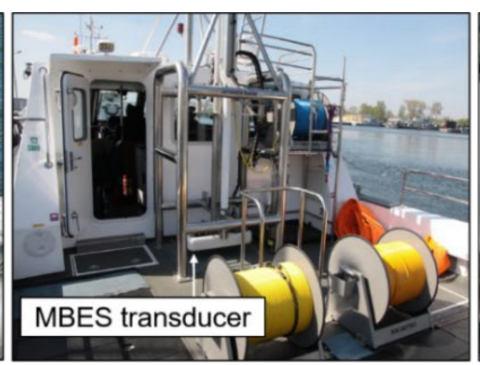

(b)

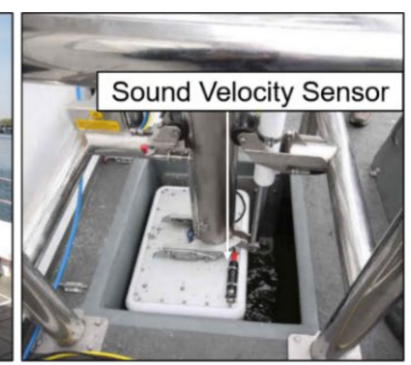

(c)

Figure 7. Moon pool installation on board Polish Navy Hydrographic Catamaran MH2, length 12 m. (a) Silhouette of Catamaran MH2; (b) multibeam echosounder transducer mounted on moon pool; (c) sound velocity sensor installed close to transducer. 
The advantage of fixed mounting of the transducer to the hull is the stability and durability of the structure. The position of the transducer is essentially steady, so one does not need to perform a patch test calibration as often as with a portable configuration. Unfortunately, when replacing or repairing the MBES transducers, it is necessary to dock the vessel in a shipyard.

The second method of installation of a multibeam echosounder transducer on board survey vessel is so-called external, portable mounting and applies to transducers operating in higher frequency bands, which are much smaller in size $(35-40 \mathrm{~cm})$ and weight. This option is most often found on smaller vessels (5-9 $\mathrm{m}$ long) surveying in shallow water areas. There are three technical solutions: (1) over-the-side transducer, (2) over-the-bow transducer, and (3) stern-mount. The transducer is mounted on a special plate at the end of a rigid pole (Figure 8 ). The bracket is attached to the hull or superstructure, usually with swivel flanges, and may be hinged or retractable. In order to ensure proper stability and rigidity of the structure, one of the pole holding brackets should be mounted as close to the waterline as possible.

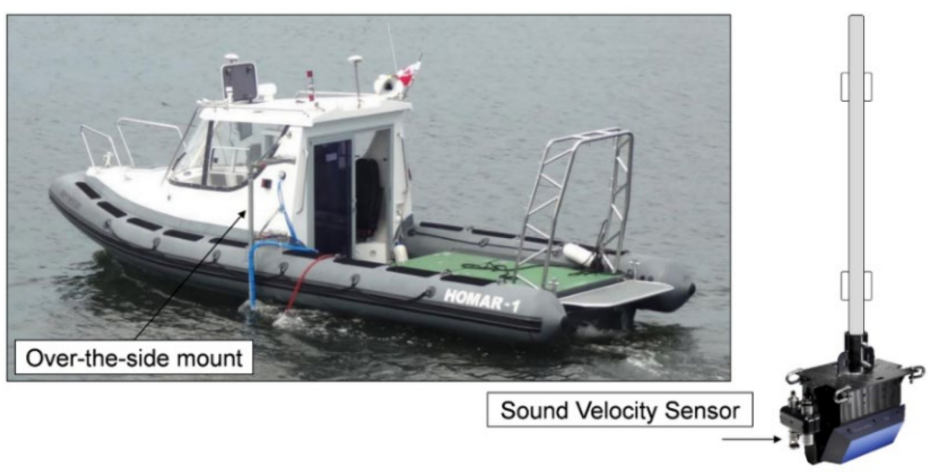

Figure 8. Polish Navy rigid inflatable boat (RIB) equipped with Kongsberg GeoAcoustics GeoSwath Plus echosounder mounted over-the-side.

The basic requirement of a portable structure is rigidity and resistance to bending. In the portable option, the undoubted advantage is direct access to the transducer, thanks to which it is possible to carry out periodic inspections, remove marine growth, and perform quick replacement or repair of the transducer. The over-the-side mount excludes in a way the possibility of mooring the vessel with the side on which the pole is installed. This method is susceptible to roll, therefore proper compensation of the angles will determine the quality of the recorded data. The small size and weight of the transducer increase the mobility of such a system and the possibility of installation on various types of vessels.

Over-the-bow mounting bracket (Figure 9) provides adequate rigidity, stability and the clear sector of acoustic ensonification. The transducer can be lowered on a special structure installed on the stem. The mechanism of lowering the sonar head to survey position is hydraulic or manual.
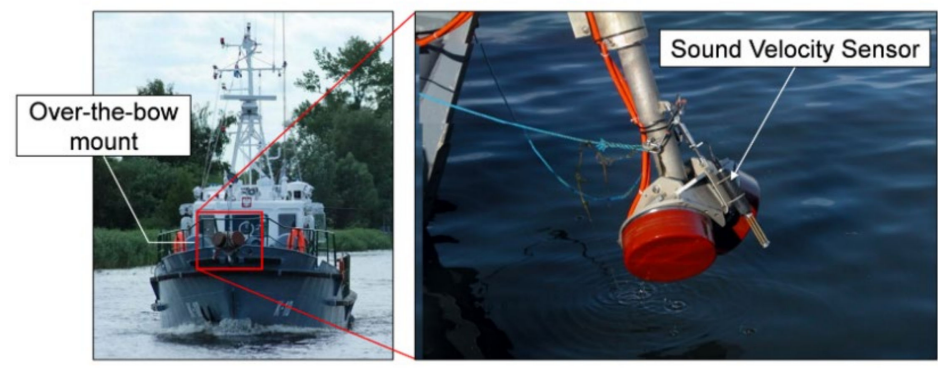

Figure 9. Polish Navy hydrographic cutter equipped with Kongsberg Maritime EM3002D multibeam echosounder mounted over-the-bow. Sound velocity sensor is mounted at the end of the pole, between transducers. 
Stern-mounted transducer is not a common solution. It is used on platforms with outboard motors, mainly as part of a one-off project. Stern installation should be paid special attention due to phenomenon of aeration from the propellers, which may significantly reduce the operating range.

\subsection{Multibeam Echosounder System on Board Polish Navy Hydrographic Ship Arctowski}

A few years ago, the hydrographic survey ship of the Polish Navy Arctowski was equipped with a Kongsberg Maritime EM3002D multibeam echosounder. The EM3002D is a dual head configuration system with a mounting tilt angle of the single sonar head $40^{\circ}$ (Figure 10). An angular swath coverage is more than $180^{\circ}$. That means the system is able to image out to above the horizontal. The array lengths used in an EM3002D result in $1.5^{\circ}$ by $1.5^{\circ}$ beams at broadside. The least operational depth is from less than $1 \mathrm{~m}$ below transducer, and under common sea water conditions the echosounder operates to $150 \mathrm{~m}$ depth.

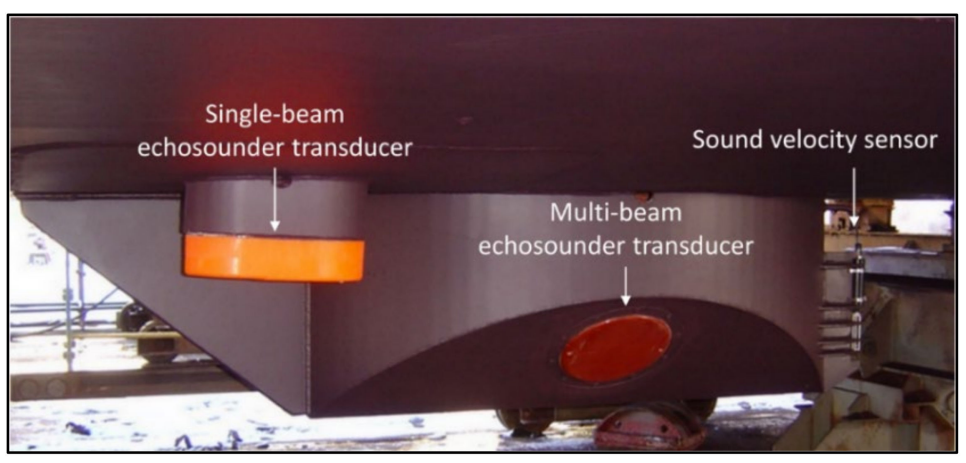

Figure 10. Under-keel blister with multibeam, single-beam transducers, and sound velocity sensor.

The EM3002D is a so-called flat or linear configuration, which consists of two linear arrays installed perpendicular to each other, often called a Mills Cross configuration. As the sonar heads are tilted to port and starboard it is suggested to mount a sensor to allow real-time measurement of the surface sound velocity [46]. The echosounder will then take into account the sensor measurements in its computations of beam steering angles and corrections for bending of the acoustic ray. The EM3002 is compensated for both roll and pitch due to its electronic pitch compensation system and roll stabilized beams. Pitch stabilization is achieved by directing the transmit beam electronically forward or backward at the time of the pulse transmission, based on data coming from the motion reference unit.

The signal frequency of the multibeam echosounder is nominally $300 \mathrm{kHz}$. All beamforming is strictly performed with a time delay technique. There are 160 simultaneous receive beams for each transducer array. They are either distributed in the pattern of equal distances or equal angles within the coverage set by the operator. A high-density mode provides 254 depth measurements recorded by one transducer and ping [47]. EM3002D was delivered with the mini SVS sensor (Valeport), mounted in the rear part of the blister (Figure 6). Unfortunately, after several months of operation some problems with the sensor appeared.

\subsection{Cause of Sound Velocity Sensor Malfunction and ad hoc Solutions}

SVS calculates the parameter of velocity of sound in the water at the depth of MBES transducer. This information is sent to the MBES system where it is used in the process of depth calculation. After some time, communication errors appeared between the sensor and processing unit of the multibeam echosounder. Over time, these problems intensified and finally the signal from SVS disappeared. Divers performing systematic inspections did not report any problems with the sensor. After docking the ship in the yard, it turned out that the sensor was all overgrown with mussels, there was neither acoustic reflector nor spacer rods (Figure 11). 


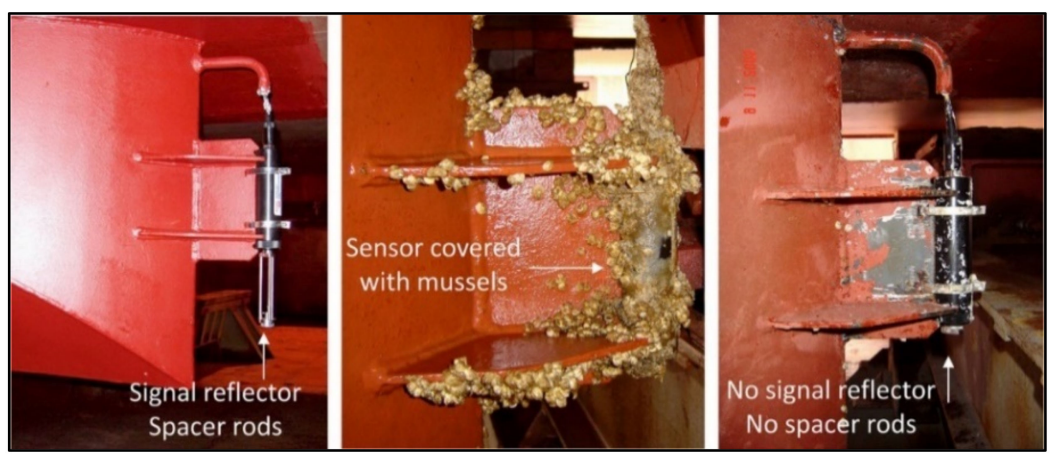

Figure 11. Technical condition of the sound velocity sensor after 2 years of operation.

As one can easily see from Figure 11, the sensor was exposed to damage and the phenomenon of overgrowing with vegetation and mussels. Consequently, the sensor did not work properly, sent incorrect values and communication errors occurred. After two years of operation of the multibeam system, the ship was planned for dock repair at the shipyard. Some experience and conclusions were gathered. After consultation with equipment supplier, mounting steel bracket was extended and the structure was reinforced with special ribs (Figure 12).
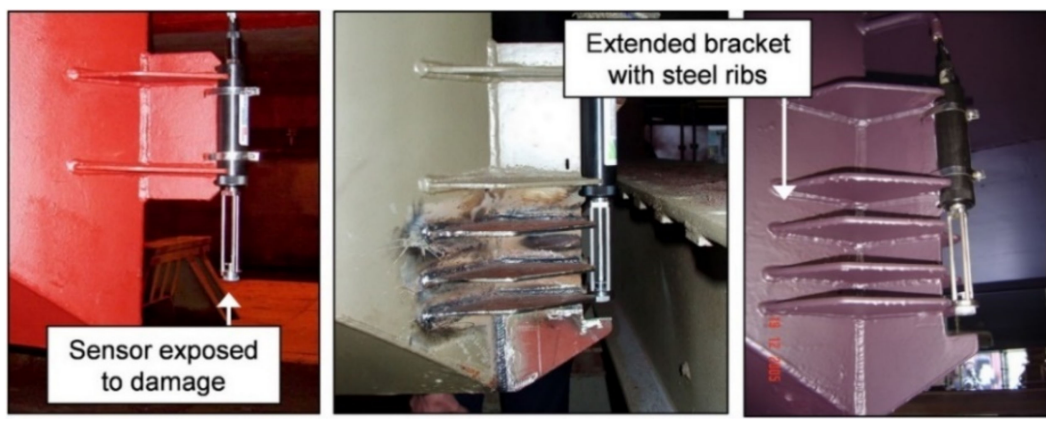

Figure 12. The first technical solution to increase the protection of sound velocity sensor.

The task of new flat steel bars was the protection of the sensor against possible damage or loss. The new mounting only partially solved the problem. It was expected that this new shape of the bracket would increase the protection of the sensor itself, however, direct access to SVS was still possible only through a diver or after docking the ship. Unfortunately, after several months of operation, it turned out that the above solution did not quite fulfill its task. The method of mounting and securing the sensor did not protect it from the damage, fouling of mussels and shells, and the occurrence of communication error. The degree of fouling with marine vegetation was so large that it often prevented its disassembly by a diver.

In the next years of operation of the multibeam echosounder, the sound velocity sensor was working properly, but occasionally, especially in the spring-autumn period, frequent communication errors were observed. Intense fouling phenomenon caused the generation of incorrect values of the surface sound speed or the complete lack of signal from the sensor. Due to this situation, bathymetric surveys for the cartographic purpose and safety of navigation were suspended. SVS was disassembled, cleaned, checked in operation and then it was placed in a special protective tube. The tube had a bottom and overflow holes (Figure 13). The sensor was reinstalled using a team of divers. 


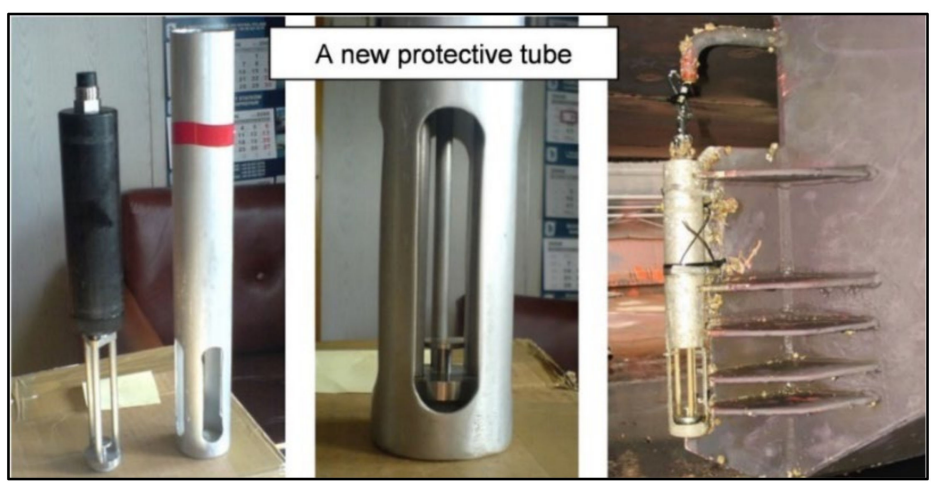

Figure 13. Sound velocity sensor placed in a special protective tube.

After several months of performing hydrographic surveys and using SVS, problems of signal transmission appeared again. Although the transducer, acoustic reflector and spacer rods were fully protected, problem of mussels growing still existed. This phenomenon intensified especially after the ship was moored at a port for a long time. The cleaning of the acoustic reflector by a diver was somewhat difficult due to the reduced access to individual parts of the sensor (Figure 14). Therefore, the only way to improve the performance of SVS was to disassemble the sensor with a diver, cleaning on board and reinstalling it underwater.

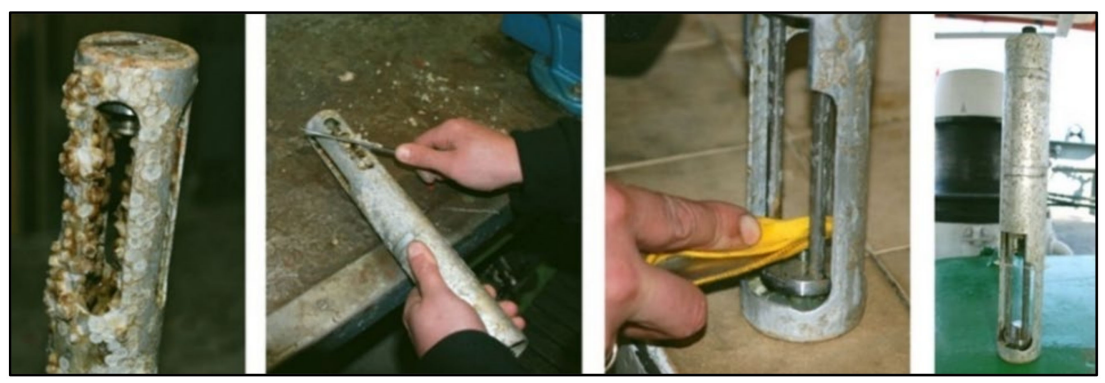

Figure 14. Cleaning the sound velocity sensor after disassembly by a diver.

\section{Results and Discussion}

After all possible methods of protection of the sound velocity sensor were exhausted, hydrographers of the survey vessel Arctowski came up with an idea how to solve an existing problem effectively. A great opportunity for implementation a new solution was a planned ship repair in the yard. According to the list of modernization and replacement of the ship's equipment the old electromagnetic log was to be removed. The main part of the $\log$ was the measuring head lowered from the bottom of the ship using a log lifter. After the disassembly of the log, the concept of using the existing hole in the keel appeared (Figure 15). It was decided to adapt this place to the sound velocity sensor.

In order to change the mounting spot of the sound velocity sensor, the lifter previously working with electromagnetic log had to be adapted to a new device. For this purpose, a special protective bracket was designed and made in the form of a brass tube. It was to be a kind of sensor external housing (Figure 16). This tube was threaded at one end and screwed into the guide bar. The sensor was placed in a tube, which was secured against falling out with a nut. The whole construction was adjusted so that it could fit in the lifter and functioned like the electromagnetic log head. The mechanism of the lifter made it possible to lower the sensor, raise it above the water line and close the valve (wedge slide). 


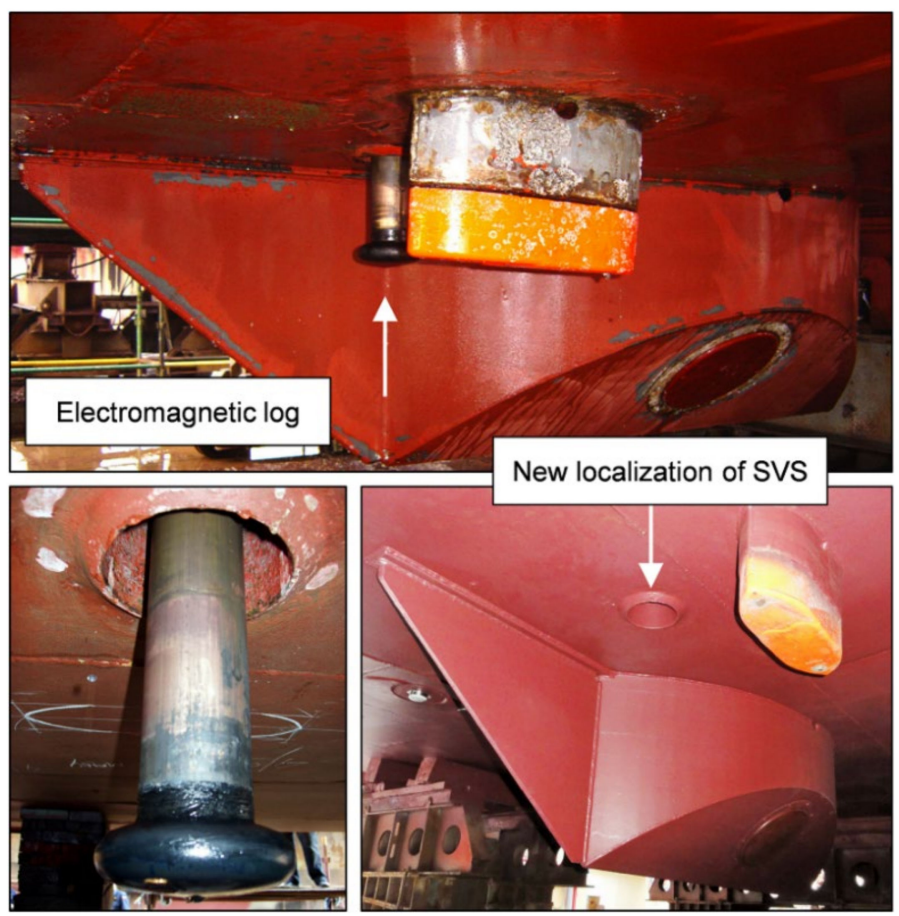

Figure 15. Electromagnetic log head in a lowered position and a new sound velocity sensor location.

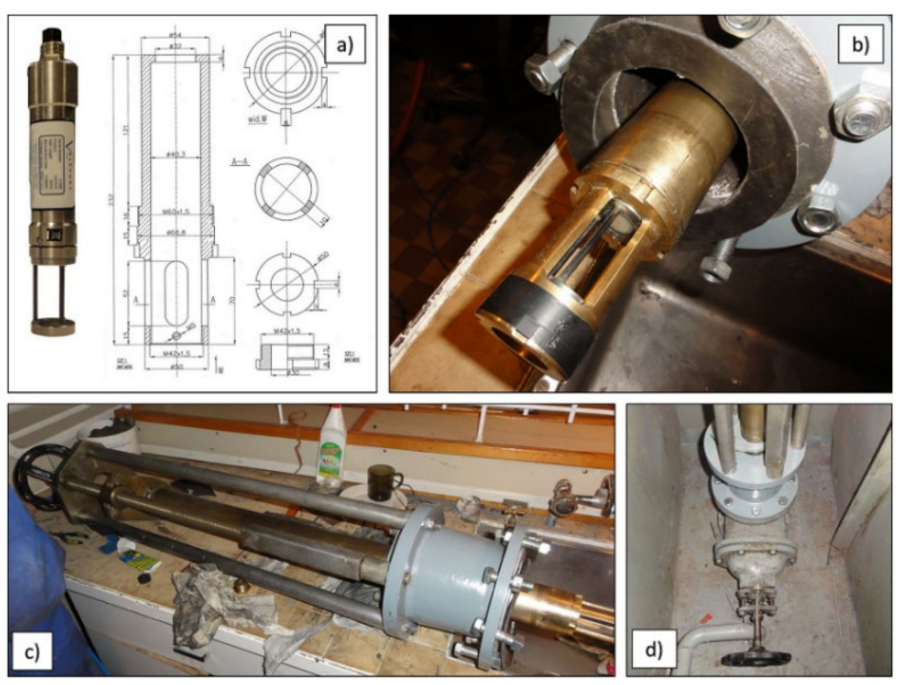

Figure 16. Components of the technical solution implemented on board Polish Navy hydrographic ship Arctowski. (a) Sound velocity sensor and technical design of brass tube; (b) sensor mounted in the tube attached to the log lifter; (c) modernized log lifter; (d) valve in the bottom of the ship's hull.

In the over-the-side mounts the SVS sensor is mounted on the same plate or pole as the transducer in close proximity to it. In these solutions, the operator has direct access to the sensor and the transducer itself. Hence, it is possible to inspect or replace a sensor without a need to dock the ship. In fixed installations such as a gondola, blister or flush mount, the SVS sensor is often mounted to the steel, underwater structure.

In the case of newly built vessels, at the design stage, it is possible to plan a suitable valve in the keel with a bottom opening for SVS sensor. Arctowski was built in 1982 (39 years ago) and the first MBES was installed in 2003 (after 21 years). At the time of MBES installation the only possible solution was to install the sonar heads in a blister with the sound speed sensor connected to the rear part of it. Such a solution was not sufficient and effective, as the ship's hydrographers found out. 
In the applied solution the SVS is lowered below the keel only when performing hydrographic survey. In the following years, the hydrographers from Arctowski very rarely noticed any errors or communication problems with the sensor. Direct access to the sensor made it possible to conduct periodic inspections, cleaning and calibration of the sensor, which was not possible in previous technical solutions. The new practical concept (Figure 17) improved the accuracy of surface sound velocity measurements and as a result the quality of bathymetric data acquired with multibeam echosounder.
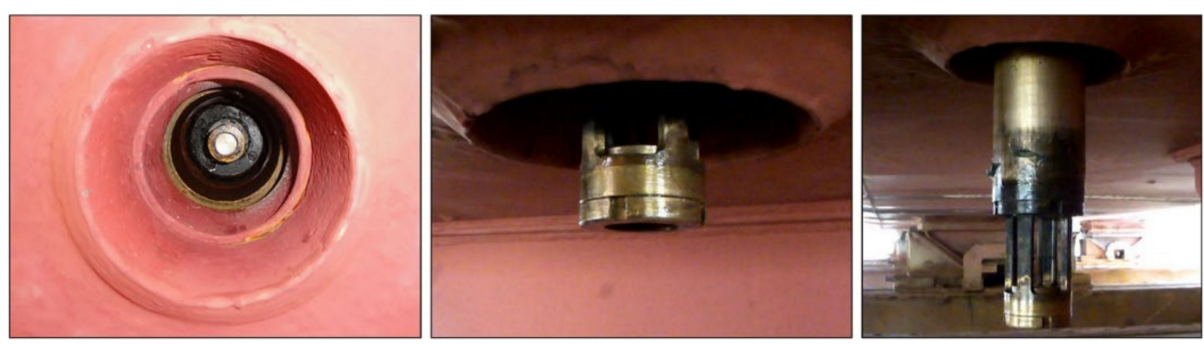

Figure 17. The new location of under-keel sound velocity sensor.

The refractive error can be improved by introducing the correct sound velocity profile in the water column. Beam steering error cannot be corrected because it is a part of the beam data. The analysis carried out clearly shows that the implementation of the technical solution will increase the service life of the under-keel sound velocity sensor. This will eliminate the situation of conducting hydrographic surveys with a faulty sensor, which may result in recording erroneous bathymetric data for the cartographic purpose and safety of navigation. In addition, if the sensor needs to be replaced with a new one or cleaned, there will not be any necessity to dock the ship or use the diver.

After the implementation of a new method of SVS installation, multibeam surveys were undertaken in the same survey area. No measurement artifacts were found in the zones of outer acoustic beams (Figure 18). Thus, the final bathymetric chart reflected the actual depth distribution and met the accuracy requirements set by the Hydrographic Office of the Polish Navy (Figure 19).
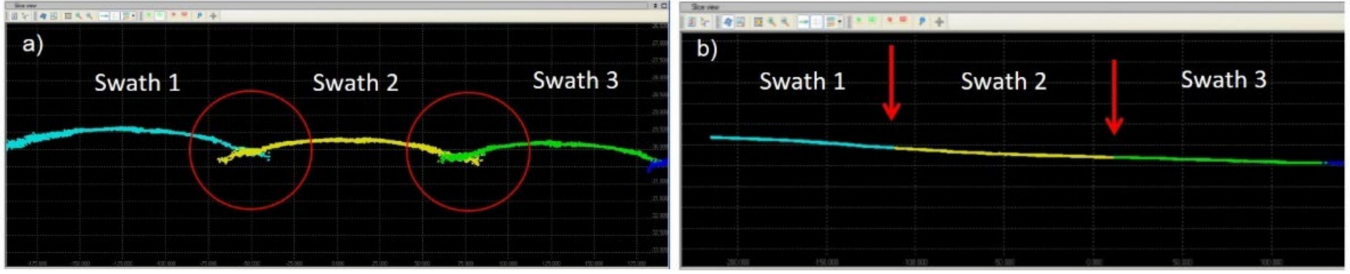

Figure 18. Comparison of multibeam echosounder depth measurement results with (a) the faulty sound velocity sensor and (b) with the sensor installed in a new under-keel location. 


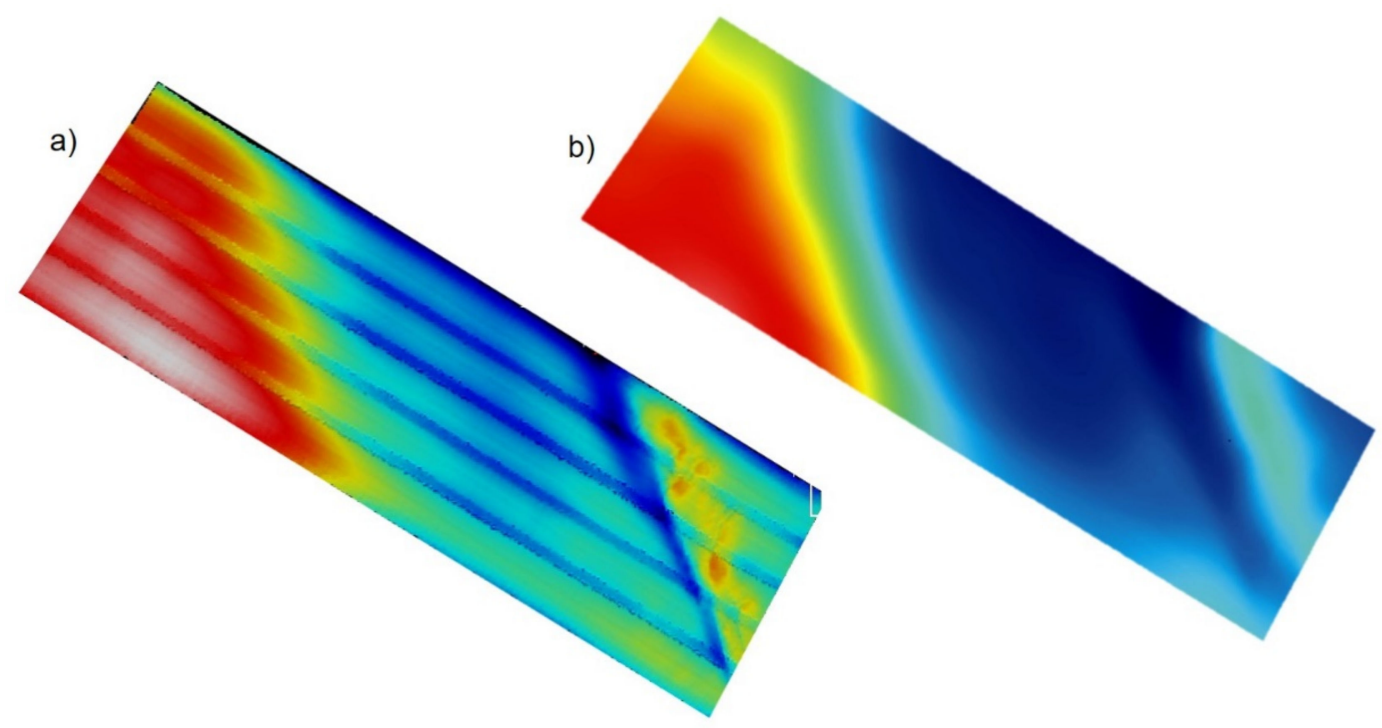

Figure 19. Depth distribution in the area obtained using the multibeam echosounder with the faulty SVS (a) and with the sensor installed according to a new technical solution $(\mathbf{b})$.

\section{Conclusions}

The main purpose of the submitted project was to improve the operation of the EM3002D multibeam echosounder system installed on board the Polish Hydrographic Survey Ship Arctowski. The essence of the solution was to change the mounting location of the sensor and to adapt the existing hole in the bottom and valve to a new equipment. The sensor was moved from the permanent attachment behind the blister to the log room inside the ship. This change was indispensable due to systematic malfunction and troubleshooting of the sensor as well as limited access to the device. In the new solution, SVS is lowered from the bottom of the ship into the water (a few to several centimeters) using a modernized lifter adapted to the sensor.

The most valuable advantage of the reported solution is the possibility of disassembling the sensor from inside the ship without the diver help or expensive operation of docking the ship. This improvement will positively impact both functioning of the sound velocity sensor itself and the entire multibeam echosounder system.

The implemented solution completely changes the idea of periodic inspections, maintenance and cleaning of the sound velocity sensor on board hydrographic survey ship Arctowski. The solution allows disassembly and assembly of SVS without the participation of divers or the need for expensive docking operations. The proposed concept certainly will allow for conducting a continuous and accurate bathymetric survey and extending the life of sensor, reducing the risk of damage or malfunction. In the case of sensor damage, the time to reach the ship's readiness to perform survey is only conditioned by the time the sensor is repaired or the delivery of a new one. The need to dock the ship disappears.

Funding: This research received no external funding.

Institutional Review Board Statement: Not applicable.

Informed Consent Statement: Not applicable.

Data Availability Statement: Not applicable.

Acknowledgments: The author would like to thank the crew of the Polish Navy Hydrographic Ship Arctowski, for their dedication, exemplary performance of tasks and a fantastic atmosphere onboard during over 18 years of service.

Conflicts of Interest: The author declares no conflict of interest. 


\section{References}

1. Grządziel, A. The Influence of the Multibeam Swath Angle on the Accuracy of Hydrographic Survey. Ph.D. Thesis, Polish Naval Academy, Gdynia, Poland, 2019.

2. Wölfl, A.-C.; Snaith, H.; Amirebrahimi, S.; Devey, C.W.; Dorschel, B.; Ferrini, V.; Huvenne, V.A.I.; Jakobsson, M.; Jencks, J.; Johnston, G.; et al. Seafloor Mapping-The Challenge of a Truly Global Ocean Bathymetry. Front. Mar. Sci. 2019, 6, 283. [CrossRef]

3. Bowditch, N. The American Practical Navigator; Volume I, Pub. No.9; National Geospatial-Intelligence Agency: Springfield, VA, USA, 2017.

4. Mayer, L.; Jakobsson, M.; Allen, G.; Dorschel, B.; Falconer, R.; Ferrini, V.; Lamarche, G.; Weatherall, H.S.P. The nippon foundationGEBCO seabed 2030 project: The quest to see the world's oceans completely mapped by 2030. Geosciences 2018, 8, 63. [CrossRef]

5. Smith, S. Seabed 2030: A Call to Action. Hydro Int. 2018, 22, 22-23.

6. Blondel, P. Bathymetry and Its Applications; InTech: Rijeka, Croatia, 2012; ISBN 9789533079592. [CrossRef]

7. Gao, J. Bathymetric mapping by means of remote sensing: Methods, accuracy and limitations. Prog. Phys. Geogr. 2009, 33, 103-116. [CrossRef]

8. IHO. Intergovernmental Oceanographic Commission, The IHO-IOC GEBCO Cook Book; Publication B-11: Monaco City, Monaco, $2014 ; 331 \mathrm{p}$.

9. Lurton, X. An Introduction to Underwater Acoustics: Principles and Applications, 2nd ed.; Springer Science \& Businesss Media: Berlin, Germany, 2010.

10. Grządziel, A.; Wąż, M. Estimation of effective swath width for dual-head Multibeam Echosounder. Annu. Navig. 2016, 23, 173-183. [CrossRef]

11. Stateczny, A.; Błaszczak-Bąk, W.; Sobieraj-Żłobińska, A.; Motyl, W.; Wisniewska, M. Methodology for Processing of 3D Multibeam Sonar Big Data for Comparative Navigation. Remote Sens. 2019, 11, 2245. [CrossRef]

12. Yan, Z.-L.; Qin, L.-L.; Wang, R.; Li, J.; Wang, X.-M.; Tang, X.-L.; An, R.-D. The Application of a Multi-Beam Echo-Sounder in the Analysis of the Sedimentation Situation of a Large Reservoir after an Earthquake. Water 2018, 10, 557. [CrossRef]

13. Haga, K.H.; Pohner, F.; Nilsen, K. Testing multibeam echosounders versus IHO S-44 requirements. Int. Hydrogr. Rev. 2003, 4, $31-40$.

14. Hughes Clarke, J.E.; Mayer, L.A.; Wells, D.E. Shallow-water imaging multibeam sonars: A new tool for investigating seafloor processes in the coastal zone and on the continental shelf. Mar. Geophys. Res. 1996, 18, 607-629. [CrossRef]

15. International Hydrographic Organization. Manual on Hydrography, IHO C-13, 1st ed.; International Hydrographic Organization: Monaco City, Monaco, 2011.

16. International Hydrographic Organization. Standards for Hydrographic Surveys, Special Publication No 44, 5th ed.; International Hydrographic Organization: Monaco City, Monaco, 2008.

17. Kearns, T.A. Remote Sensing and Multibeam Hydrography. Sea Technol. 2002, 10, 21-27.

18. Mitchell, N.C.; Hughes-Clarke, J.E. Classification of seafloor geology using multibeam sonar data from the Scotian Shelf. Mar Geol. 1994, 121, 143-160. [CrossRef]

19. Courtney, R.C.; Shaw, J. Multibeam bathymetry and back-scatter imaging of the Canadian continental shelf. Geosci. Can. 2000, 27, 31-42.

20. Moustier, C. Beyond bathymetry: Mapping acoustic backscatter from the deep seafloor with Sea Beam. J. Acoust. Soc. Am. 1986, 79, 316-331. [CrossRef]

21. Preston, J. Acoustic Classification by Sonar. Hydro Int. 2004, 8, $23-25$.

22. Todd, B.J.; Fader, G.B.J.; Courtney, R.C.; Pickrill, R.A. Quaternary geology and surficial sediment processes, Browns Bank, Scotian Shelf, based on multibeam bathymetry. Mar Geo. 1999, 162, 165-214. [CrossRef]

23. Orange, D.L.; Yun, J.; Maher, N.; Barry, J.; Greene, G. Tracking California seafloor seeps with bathymetry, backscatter and ROVs. Cont. Shelf Res. 2002, 22, 2273-2290. [CrossRef]

24. Kostylev, V.E.; Todd, B.J.; Fader, G.B.J.; Courtney, R.C.; Cameron, G. Benthic habitat mapping on the Scotian Shelf based on multibeam bathymetry, surficial geology and seafloor photographs. Mar. Ecol. Prog. Ser. 2001, 219, 121-137. [CrossRef]

25. Díaz, J.V.M. Analysis of Multibeam Sonar Data for the Characterization of Seafloor Habitats. Master' Thesis, The University of New Brunswick, Fredericton, Canada, 1999. Available online: http://hidrografica.tripod.com/Analysis_MB_SeafloorHabitats. pdf (accessed on 21 July 2020).

26. Hydro International. Multi-Beam Echo Sounders; Geomares: Lemmer, The Netherlands, 2010.

27. Lucieer, V.; Picard, K.; Siwabessy, J.; Jordan, A.; Tran, M.; Monk, J. Seafloor mapping field manual for multibeam sonar. In Field Manuals for Marine Sampling to Monitor Australian Waters; Przeslawski, R., Foster, S., Eds.; National Environmental Science Programme (NESP): Tasmania, Australia, 2018; pp. 42-64. Available online: https:/ /www.nespmarine.edu.au/field-manuals (accessed on 25 October 2019).

28. Lekkerkerk, H.-J.; Theijs, M.J. Handbook of Offshore Surveying, 2nd ed.; Volume 3-Acquisition Sensors; Skilltrade BV: Voorschoten, The Netherlands, 2012; ISBN 978-90-816591-3-0.

29. Demer, D.A.; Berger, L.; Bernasconi, M.; Bethke, E.; Boswell, K.; Chu, D.; Domokos, R.; Dunford, A.; Fassler, S.; Gauthier, S.; et al. Calibration of Acoustic Instruments; ICES Cooperative Research Report No. 326; ICES: Copenhagen, Denmark, 2015; 133p. [CrossRef] 
30. Ernstsen, V.B.; Noormets, R.; Hebbeln, D.; Bartholomä, A.; Flemming, B.W. Precision of high-resolution multibeam echo sounding coupled with high-accuracy positioning in a shallow water coastal environment. Geo-Mar. Lett. 2006, 26, 141. [CrossRef]

31. Hare, R.; Eakins, B.; Amante, C. Modelling bathymetric uncertainty. Int. Hydrogr. Rev. 2011, 6, 31-42.

32. Didier, C.; Jaouad, E.; Gaspard, G.; Michel, L. Real-time correction of sound refraction errors in bathymetric measurements using multiswath multibeam echosounder. In Proceedings of the OCEANS 2019-Marseille, Marseille, France, 17-20 June 2019; pp. 1-7. [CrossRef]

33. Beaudoin, J.; Calder, B.R.; Hiebert, J.; Imahori, G. Estimation of Sounding Uncertainty from Measurements of Water Mass Variability. Int. Hydrogr. Rev. 2009. ISSN: 0020-6946.

34. Mohammadloo, T.H.; Snellen, M.; Renoud, W.; Beaudoin, J.; Simons, D.G. Correcting Multibeam Echosounder Bathymetric Measurements for Errors Induced by Inaccurate Water Column Sound Speeds. IEEE Access 2019, 7, 122052-122068. [CrossRef]

35. Hammerstad, E. Multibeam Echo Sounder Accuracy, Internal Kongsberg Simrad Publication-EM Technical Note; Kongsberg Maritime AS: Horten, Norway, 2001.

36. Batton, D. The effect of refraction on oblique angles of multibeam echo-sounders due to sound speed changes through the water column. Hydrogr. J. 2004, 113, 15-20.

37. Kammerer, E. New Methods for Removal of Refraction Artifacts in Multibeam Echosounder Systems. Ph.D. Thesis, The University of New Brunswick, Fredericton, NB, Canada, 2000; p. 220.

38. Motao, H.; Guojun, Z.; Yongzhong, O.; Yanchun, L. Data fusion technique for multibeam echosoundings. Geo-Spat. Inf. Sci. 2002, 5, 11-18. [CrossRef]

39. Hare, R. Error Budget Analysis for US Naval Oceanographic Office Hydrographic Survey Systems; Final Report for Task 2; FY 01; University of Southern Mississippi: Hattiesburg, MS, USA, 2001; p. 153.

40. Brown, J.; Noll, G. Multibeam Sonar Data Acquisition Systems: A Simplified Conceptual Model, National Oceanic and Atmospheric Administration; Technical Memorandum NOS CS 3; NOAA: Silver Spring, MD, USA, 2003.

41. Kongsberg Maritime AS. Operators Manual-EM Series Datagram Format; Kongsberg Maritime AS: Horten, Norway, 2006.

42. Beaudoin, J.D.; Hughes Clarke, J.E.; Bartlett, J. Application of surface sound speed measurements in postprocessing for multisector multibeam echosounders. Int. Hydrogr. Rev. 2004, 5, 1-16.

43. Salamon, R. Hydrolocation Systems; Gdańskie Towarzystwo Naukowe: Gdańsk, Poland, 2006; p. 807. ISBN 83-87359-98-X. (In Polish)

44. U.S. Army Corps of Engineers. Hydrographic Surveying; Publication no. EM 1110-2-1003; U.S. Army Corps and of Engineers: Washington, DC, USA, 2004. Available online: https://www.publications.usace.army.mil/USACE-Publications/EngineerManuals / ?udt_43544_param_page=4 (accessed on 3 January 2020).

45. IMCA. Guidelines for the Use of Multibeam Echosounder for Offshore Surveys; IMCA S 003 Rev. 2; International Marine Contractors Association: London, UK, 2015.

46. Kongsberg Maritime AS. EM 3002 Multibeam Echo Sounder; Kongsberg Maritime AS: Horten, Norway, 2004.

47. Grządziel, A.; Wąż, M. The mutlibeam echosounder in bathymetric survey of planned shipping routes. Logistyka 2014, 6 , 4250-4256. (In Polish) 